\title{
Degrading Pesticides with Waste Product: Imidazole-Functionalized Rice Husk Catalyst for Organophosphate Detoxification
}

\author{
José G. L. Ferreira and Elisa S. Orth* \\ Departamento de Química, Universidade Federal do Paraná(UFPR), \\ CP 19081, 81531-990 Curitiba-PR, Brazil
}

\begin{abstract}
Rice husk (RH) is one the largest agricultural waste products worldwide, and rice is one of the crops that use the most pesticides. Among these, organophosphates have been of increasing concern due to their high toxicity. Herein, we report the functionalization of RH with imidazole groups (RHIMZ) to obtain sustainable catalysts from waste for organophosphate degradation. The waste-derived catalyst showed prominent catalytic activity in dephosphorylation reactions with the model substrate diethyl 2,4-dinitrophenyl phosphate (DENDPP), over $10^{5}$-fold, compared to the spontaneous reaction (lifetime $=1$ month). Finally, RHIMZ was also effective in degrading the pesticide Paraoxon (spontaneous lifetime $=1$ million years), degrading $60 \%$ in 20 days, giving a $10^{7}$-fold enhancement. Overall, the proposed approach is environmentally friendly for reusing the waste for a noble cause, i.e., degrading toxic pesticides, which is promising for designing sensors and detoxification processes.
\end{abstract}

Keywords: rice husk, sustainable catalyst, imidazole, pesticide degradation, organophosphate, rice husk functionalization

\section{Introduction}

Rice husk (RH) comprises one of the largest agricultural waste products, with the inherent waste management concerns. ${ }^{1}$ Notwithstanding, while rice feeds more than half of the human population, about $0.22 \mathrm{~kg}$ of $\mathrm{RH}$ is produced for each $1 \mathrm{~kg}$ of rice cropped, i.e., an estimated production of 164 million tons of RH only in 2013, according to data of FAOSTAT. ${ }^{2,3}$ Furthermore, RH leads as the most underused cellulosic source in contrast to wood, textile fibers and papers. RH is composed of $75-80 \%$ of organic matter, which corresponds nearly to $44 \%$ of cellulose, $31 \%$ of hemicellulose and $25 \%$ of lignin. ${ }^{4,5}$ When burned $\left(550-600{ }^{\circ} \mathrm{C}\right), \mathrm{RH}$ ash configures as the cereal residue with the highest percentage of $\mathrm{Si}(94.38,2.29$ and $0.97 \%$ of $\mathrm{SiO}_{2}, \mathrm{~K}_{2} \mathrm{O}$ and $\mathrm{CaO}$, respectively, and traces of $\mathrm{P}_{2} \mathrm{O}_{5}$, $\mathrm{Al}_{2} \mathrm{O}_{3}, \mathrm{MgO}, \mathrm{Fe}_{2} \mathrm{O}_{3}, \mathrm{Na}_{2} \mathrm{O}$ and $\left.\mathrm{TiO}_{2}\right) .{ }^{5}$ Despite these facts, research and use of cellulosic residues such as raw $\mathrm{RH}$ in the chemical industry is still a relatively unexplored field, thus the main destination of these materials is to burn as biomass or use as fertilizer. ${ }^{1}$

The RH waste awareness is potentiated by some facts: rice is among the major crops worldwide, which is

*e-mail: elisaorth@ufpr.br also one that most applies agrochemicals. ${ }^{6,7}$ Specifically concerning Brazil's scenario, while it occupies fourth place in worldwide agricultural production, Brazil is one of the largest consumers of agrochemicals. This has become a serious public health issue, since poisoning by pesticides is alarmingly high, losing only to medical drug. Moreover, studies show that nearly $30 \%$ of food samples (2011-2012) contain prohibited substances or are present in abusive amounts. ${ }^{8}$ This scenario along with the worldwide concern in preventing hunger and assuring safe food has increased the interest in studies regarding reactions with toxic pesticides, especially organophosphates, with potential for developing efficient monitoring and detoxifying procedures. Curiously, abandoning the use of agrochemicals does not seem as a viable option since studies show that organic agricultural is still low worldwide (Brazil is under $0.3 \%$ of agricultural area $)^{8,9}$ and surely cannot meet the food demand. Insofar, studies show that the world crop production is significantly lower than the demand projected until 2050 and that should at least double in order to feed the population..$^{10}$

Organophosphates (OP) are a class of agrochemicals of particular interest due to their high toxicity and stability. ${ }^{11-13}$ Degrading, i.e., detoxifying, these agents is challenging ${ }^{14,15}$ and analogous dephosphorylation reactions have been efficiently promoted in biological 


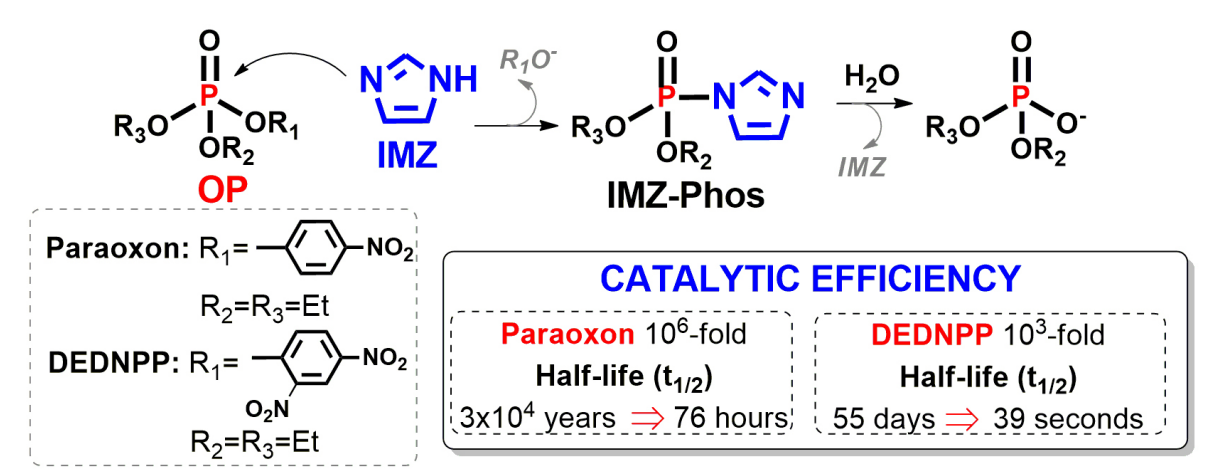

Scheme 1.

processes by enzymes. ${ }^{16}$ Thus, many bioinspired models have been proposed regarding OP degradation especially with imidazole (IMZ) groups that are present in several enzymatic active sites. ${ }^{17}$ Recently, ${ }^{16,18}$ we thoroughly elucidated the reaction of IMZ with the substrate model diethyl 2,4-dinitrophenylphosphate (DEDNPP) and the real-life pesticide Paraoxon (Scheme 1). We showed that IMZ can promote high rate enhancements $\left(10^{3}-10^{6}\right.$ fold), lowering significantly the half-life for the cleavage reaction. The mechanism involves an unstable phosphorylated intermediate that readily hydrolyses, regenerating IMZ, confirming an authentic catalysis. ${ }^{16,18}$

Based on the excellent catalytic properties of IMZ, we have pursued different scaffold for anchoring IMZ moieties such as gum arabic and graphene, seeking novel bio- and nanocatalysts. ${ }^{19,20}$ These materials have been successfully applied as catalysts with model substrates such as DEDNP but not yet with the much less reactive Paraoxon pesticide. Given the optimal properties already confirmed for IMZ-derived catalysts, herein, we propose to reuse RH waste by functionalizing it with IMZ groups leading to a catalyst targeted for OP degradation. The proposal is appealing by the sustainability point of view and OP concern perspective, since we propose to reuse waste from a crop known for its excessive pesticide usage and in counterpart apply the recycled waste as catalyst for degrading toxic pesticide such as OP.

Overall, we propose the carboxymethylation of the cellulose present in RH leading to the sample $\mathrm{RHCOOH}$, followed by functionalization with IMZ giving RHIMZ, shown in Scheme 2. All samples were characterized by Fourier transform infrared spectroscopy (FTIR), thermogravimetric analysis (TGA) and potentiometric titration. RHIMZ was evaluated as catalyst for OP degradation of DEDNPP and the pesticide diethyl 4-dinitrophenylphosphate (Paraoxon). The approach proposed is environmentally friendly and sustainable, since the catalyst obtained is biodegradable and reuses a crop residue. Finally, this work sets up a scientific breakthrough in the field of catalysis, building groundwork for future researches on the development of artificial enzymes and more efficient green catalysts. To the best of our knowledge, this is the first report regarding IMZ functionalization of RH and further application as catalysts.

\section{Experimental}

\section{Materials}

RH, N-hydroxysuccinimide (NHS), 1-ethyl3-(3-dimethylaminopropyl)carbodiimide (EDC),

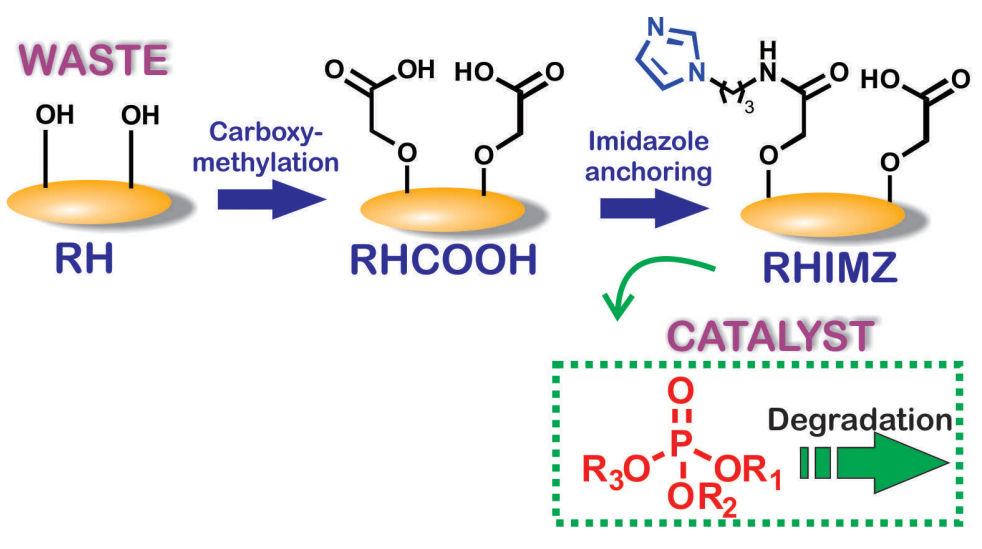


1-(3-aminopropyl)-imidazole (API), monochloroacetic acid (MCA) and Paraoxon were obtained commercially and other reactants were of analytical grade. The substrate DEDNPP was prepared as described previously. ${ }^{21}$

\section{Synthesis of $\mathrm{RHCOOH}$}

RHCOOH was prepared by a modified method of a carboxymethylation described in the literature ${ }^{22}$ as follows. RH ( $2.5 \mathrm{~g})$ was left stirring overnight at room temperature in a solution $(50 \mathrm{~mL})$ of $\mathrm{NaOH}(5.0 \mathrm{~g} ; 0.125 \mathrm{~mol})$ and MCA $(2.5 \mathrm{~g} ; 0.0265 \mathrm{~mol})$ in deionized water. The mixture was washed with $\mathrm{HCl}\left(1 \times 10^{-3} \mathrm{~mol} \mathrm{~L}^{-1}\right)$ and then with deionized water three times each. In the following, $\mathrm{RHCOOH}$ was kept stirring in deionized water for 24 hours and then it was dried at $50{ }^{\circ} \mathrm{C}$ for 2 hours and afterwards was stored.

\section{Synthesis of RHIMZ}

RHIMZ was prepared adapting the method already reported for IMZ anchoring on gum arabic. ${ }^{20} \mathrm{RHCOOH}$ $(1.7 \mathrm{~g})$ was left stirring for 2 hours in $50 \mathrm{~mL}$ of deionized water with NHS (1.04 g; $9.03 \mathrm{mmol})$ and EDC $(1.40 \mathrm{~g}$; $9.03 \mathrm{mmol})$ in a round-flask, under ice-bath. API $(1.07 \mathrm{~mL}$; $9.03 \mathrm{mmol}$ ) was added to the mixture and left stirring overnight at room temperature. The resulting solid RHIMZ was washed with deionized water several times, dried at $50{ }^{\circ} \mathrm{C}$ for 2 hours and then stored.

\section{Potentiometric titrations}

Titrations were carried out following well-established methods ${ }^{23}$ in a thermostated cell at $25.0^{\circ} \mathrm{C}$. The $\mathrm{pH}$ was monitored by a pHmeter upon addition of small increments of $\mathrm{CO}_{2}$-free $\mathrm{KOH}\left(9.95 \times 10^{-3} \mathrm{~mol} \mathrm{~L}^{-1}\right)$ using a manual burette. Aliquots of $\mathrm{HCl}\left(1.08 \times 10^{-1} \mathrm{~mol} \mathrm{~L}^{-1}\right)$ were added before titration to guarantee protonation of all species. The program BEST $7{ }^{24}$ was used to obtain the equilibrium constants and also to identify the ionic groups present (i.e., carboxyl, hydroxyl and IMZ).

\section{Catalytic activity with DEDNPP}

The catalytic activity of the samples with DEDNPP was evaluated by UV-Vis spectroscopy, following the appearance of the product 2,4-dinitrophenolate (DNP) at $400 \mathrm{~nm}$. Reactions were carried out in $3 \mathrm{~mL}$ quartz cuvettes at $21^{\circ} \mathrm{C}$, containing aqueous solutions of $\mathrm{RH}, \mathrm{RHCOOH}$ or RHIMZ (5-6 mg) under different pHs with magnetic stirring and started by adding an aliquot $(10 \mu \mathrm{L})$ of DEDNPP $\left(6.02 \times 10^{-3} \mathrm{~mol} \mathrm{~L}^{-1}\right.$ in acetonitrile). Observed first-order rate constants $\left(\mathrm{k}_{\mathrm{obs}}\right)$ were calculated from data of absorbance versus time data for at least $90 \%$ of the reaction, using an iterative least-squares program. The $\mathrm{pH}$ was buffered with $0.01 \mathrm{~mol} \mathrm{~L}^{-1}$ of $\mathrm{K}_{2} \mathrm{HPO}_{4}$ (pH 6-8) and $\mathrm{KHCO}_{3}(\mathrm{pH} 9-11$ ). To prevent microbiologic growth, $3.07 \times 10^{-3} \mathrm{~mol} \mathrm{~L}^{-1}$ of $\mathrm{NaN}_{3}$ was added in all reactions, which alone does not have catalytic activity.

\section{Catalytic activity with Paraoxon}

UV-Vis spectra were obtained at the beginning of the reaction and after 20 days. The absorbance of the 4-nitrophenolate product at $400 \mathrm{~nm}$ was measured and compared to the absorbance for the analogous reaction with total consumption of Paraoxon (100\%), thus the degradation degree was calculated. Reactions were carried out in a sealed $2 \mathrm{~mL}$ Eppendorf flask containing $5 \mathrm{mg}$ of the samples and immerse in water bath at $30^{\circ} \mathrm{C}$, by adding $10 \mu \mathrm{L}$ of the substrate Paraoxon $\left(1.2 \times 10^{-2} \mathrm{~mol} \mathrm{~L}^{-1}\right.$ in acetonitrile). The $\mathrm{pH}$ was maintained at 8.5 , with $0.01 \mathrm{~mol} \mathrm{~L}^{-1} \mathrm{~K}_{2} \mathrm{HPO}_{4}$.

\section{FTIR analysis}

The samples were characterized by FTIR on a Bio-Rad spectrophotometer over the range of $4000-400 \mathrm{~cm}^{-1}$, using the $\mathrm{KBr}$ pellet method.

TGA

TGA were carried out on a SDT Q600 equipment (TA Instruments) from TA Instruments under $100 \mathrm{~mL} \mathrm{~min}^{-1}$ $\mathrm{Ar}$ at a heating rate of $5{ }^{\circ} \mathrm{C} \mathrm{min}^{-1}$. For analysis under $\mathrm{N}_{2}$ $\left(100 \mathrm{~mL} \mathrm{~min}^{-1}\right)$, a SDT Q600 equipment (TA Instruments) was used at a heating rate of $10{ }^{\circ} \mathrm{C} \mathrm{min}{ }^{-1}$.

\section{Results and Discussion}

\section{Characterization}

In order to obtain the functionalized $\mathrm{RH}$, we were first concerned in enabling carboxylate groups on $\mathrm{RH}$, following a modified carboxymethylation method. ${ }^{22}$ This method relies on the esterification reaction of the cellulose fractions of RH with MCA, furnishing carboxylate groups as shown in Scheme 3, that occurs preferentially at the $\mathrm{C} 2$ position. ${ }^{25,26}$ The degree of functionalization, known as the number of hydroxyl groups that can be substituted (maximum 3) can lead to dissolution in water (above 0.4 ), ${ }^{22}$ which is not interesting herein. Hence, we used a milder condition for carboxymethlyation to guarantee heterogeneous catalysts and indeed the functionalized samples maintained 
overall characteristics (i.e., color and appearance; Figure 1). Unfortunately, the reported procedures ${ }^{22,25-27}$ for determining the degree of carboxymethylation were inapplicable for our samples since they usually require dissolution of the material and high cellulose composition (>90\%) or even advanced techniques such as solid nuclear magnetic resonance. We attempted colorimetric analysis for quantifying carboxylic ${ }^{20}$ and IMZ groups, ${ }^{28}$ but the complex nature of RH interfered in the analyses and no concrete conclusion was possible. For anchoring IMZ groups, we targeted the carboxylate sites of RHCOOH by the reaction with EDC, NHS and API that we had already reported for gum arabic and graphene oxide. ${ }^{19,20}$ We showed that functionalization is accomplished by means of amide bonds which is stable, therefore ideal for ensuring recyclable features for the designed catalysts. Finally, we expect low degree of IMZ anchoring, since herein we targeted low carboymethylation and we know from previous studies ${ }^{20}$ that IMZ functionalization degree is usually low (under $15 \%$ ) following the proposed methodology. Nonetheless, the approach is interesting since it requires aqueous medium and follows a straightforward procedure.

Figure 1 presents the photographs of the samples and shows some small differences. This is expected since carboxymethylation using concentrated $\mathrm{NaOH}$ should dissolve inorganic compounds, lignin and other organic compounds, which afterwards are washed out. ${ }^{29}$

Potentiometric titrations were carried out to confirm the functional groups on RH surface and the titration profiles are given in Figure 2A. The data were fitted using the program BEST $7,{ }^{24}$ which we have shown to be a powerful tool to characterize complex samples such as biopolymers and nanostructured materials. ${ }^{20,23}$ Even for low degrees of functionalization, we were able to characterize the functional groups, that other commonly used techniques cannot properly distinguish. Indeed, due to the complex nature of $\mathrm{RH}$, we expect low degrees of functionalization, as will be confirmed in the following. Results show for RHCOOH two $\mathrm{pK}_{\mathrm{a}}$ 's assigned to the carboxylic acid $\left(\mathrm{pK}_{\mathrm{a} 1}=6.06 \pm 0.05\right)$ and hydroxyl $\left(\mathrm{pK}_{\mathrm{a} 3}=9.05 \pm 0.05\right)$ moieties, as shown in Figure 2B. These values agree with other reported complex structures, i.e., typical values for hydroxyl groups, although less acidic carboxylic acid that can be accounted to the neighboring groups that increase the carboxylic acid $\mathrm{pK}_{\mathrm{a}}{ }^{20,23}$ For RHIMZ, three $\mathrm{pK}_{\mathrm{a}}$ 's were determined $\left(\mathrm{pK}_{\mathrm{a} 1}=6.14 \pm 0.02\right.$; $\left.\mathrm{pK}_{\mathrm{a} 2}=7.44 \pm 0.02 ; \mathrm{pK}_{\mathrm{a} 3}=9.52 \pm 0.02\right)$, since fitting required an additional $\mathrm{pK}_{\mathrm{a}}$, consistent with the IMZ group anchored. Commonly, IMZ has a $\mathrm{pK}_{\mathrm{a}}$ ca. 7 , and the higher value obtained has been observed previously with biopolymer and other IMZ-derived complex structures, therefore, confirms the targeted functionalization. ${ }^{20}$ Moreover, in RHIMZ, IMZ corresponds to nearly $11 \%$ of the functional groups, confirming the expected functionalization.

FTIR analysis of the samples are difficult firstly due to the complex nature of RH-derived materials and secondly because of the low degree of carboxymethylation and further IMZ functionalization targeted. Figure 3 presents the FTIR spectra obtained and when analyzing the region

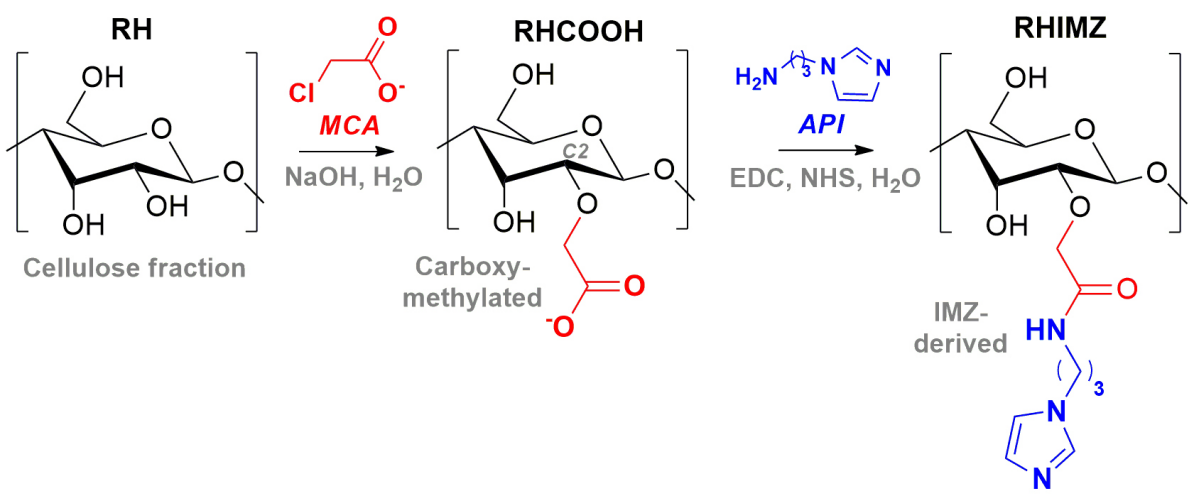

Scheme 3.

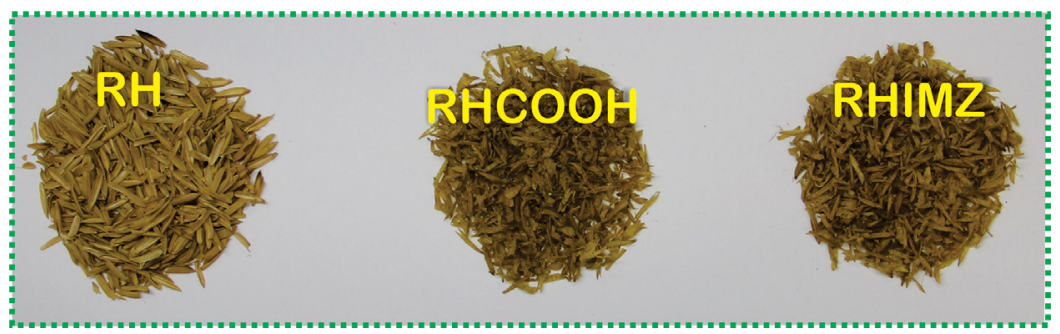

Figure 1. Photographs of the RH-derived samples. 

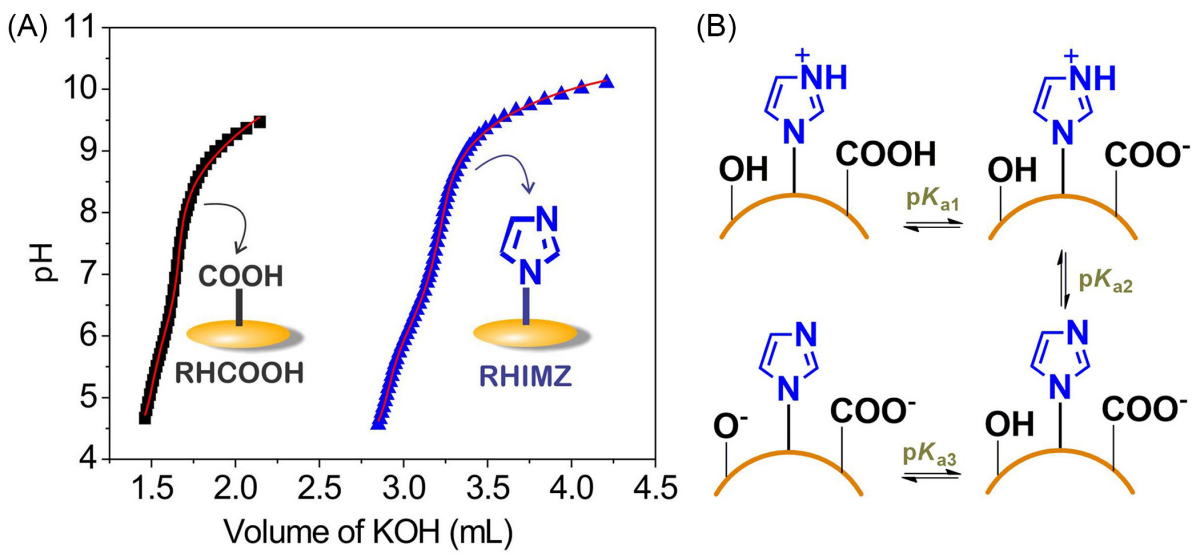

Figure 2. (A) Potentiometric titrations curves for RHCOOH and RHIMZ using $\mathrm{CO}_{2}$-free $\mathrm{KOH}\left(9.95 \times 10^{-3} \mathrm{~mol} \mathrm{~L}^{-1}\right), 25^{\circ} \mathrm{C}$. The solid red line corresponds to data fit using BEST7 ${ }^{24}$ (B) equilibria involved for RHCOOH and RHIMZ.

of $1800-400 \mathrm{~cm}^{-1}$, some differences are noticeable. The band $800 \mathrm{~cm}^{-1}$ in $\mathrm{RH}$, due to silica bonds, disappears in $\mathrm{RHCOOH}$ and RHIMZ, indicating loss of silica and other inorganic fractions, expected upon carboyxymethylation. ${ }^{29}$ The band of $1260 \mathrm{~cm}^{-1}$ is present in RHCOOH and RHIMZ that can be attributed to both $\mathrm{C}-\mathrm{O}$ and $\mathrm{C}-\mathrm{N}$ stretching. ${ }^{30,31}$ We believe this band appears in $\mathrm{RHCOOH}$, confirming carboxymethylation and in the case of RHIMZ, this band increases intensity, indicating the existence of carboxylic groups that were not functionalized, but additionally possible IMZ anchored. IMZ functionalization of RHIMZ was confirmed by the presence of the discrete band of $1558 \mathrm{~cm}^{-1}$ due to $\mathrm{C}-\mathrm{N}$ stretching and $\mathrm{N}-\mathrm{H}$ deformation. ${ }^{20,31,32}$ Moreover, we observed the band of $1640 \mathrm{~cm}^{-1}$ due to $\mathrm{C}=\mathrm{O}$ stretching, present in all samples and also $1733 \mathrm{~cm}^{-1}$ due to carbonyl vibration that decreases in RHCOOH and RHIMZ, consistent with the loss of complex organic fractions after the carboxymethylation reaction. ${ }^{29,33}$

Finally, we carried out TGA analysis under air and $\mathrm{N}_{2}$ atmosphere, shown in Figure 4. In both analyses, a first weight loss until ca. $150{ }^{\circ} \mathrm{C}$ was observed, attributed to adsorbed water. ${ }^{33}$ Furthermore, the residual mass for both TGA analyses was higher for $\mathrm{RH}$, associated with the loss of inorganic compounds (e.g., silica) upon carboxymethylation. Under air atmosphere, TGA shows two distinct weight losses: $(i)$ ca. $200-350{ }^{\circ} \mathrm{C}$ due to hemicelluloses, amorphous cellulose and other organic compounds, without significant differences between the samples; (ii) ca. $350-500{ }^{\circ} \mathrm{C}$ due to crystalline cellulose and lignin, ${ }^{34}$ and the ending temperature of this loss varied among the samples: 490,450 and $500^{\circ} \mathrm{C}$, for $\mathrm{RH}$, $\mathrm{RHCOOH}$ and RHIMZ, respectively. The decrease for $\mathrm{RHCOOH}$ in contrast to $\mathrm{RH}$ is accounted to the carboxymethylation, known to decrease the thermal stability. ${ }^{33,34}$ On the other hand, the increase for RHIMZ was attributed to the IMZ functionalization, also observed in other functionalized materials with amide and imide groups. ${ }^{35,36}$ For TGA analyses under $\mathrm{N}_{2}$, a sharp weight loss of ca. $50 \%$ from 240-370 ${ }^{\circ} \mathrm{C}$ was assigned to the hemicellulose, lignin and all the other organic compounds..$^{29,33,37}$ Additionally,

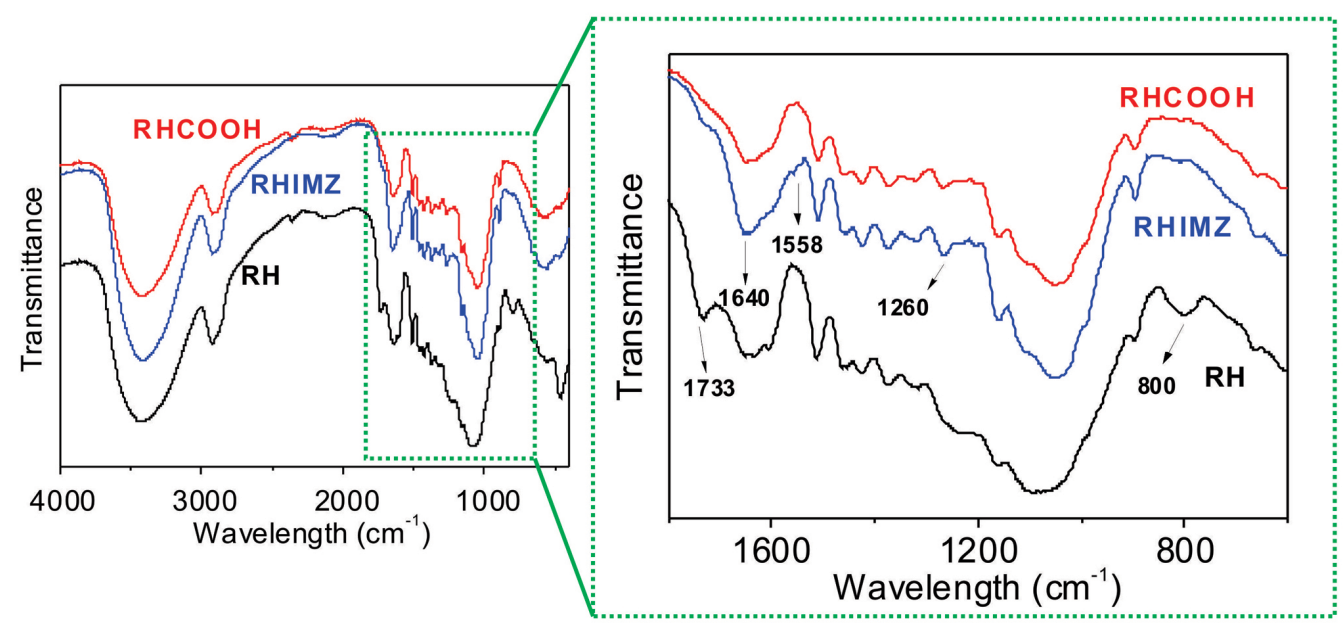

Figure 3. FTIR spectra for RH, RHCOOH and RHIMZ. 

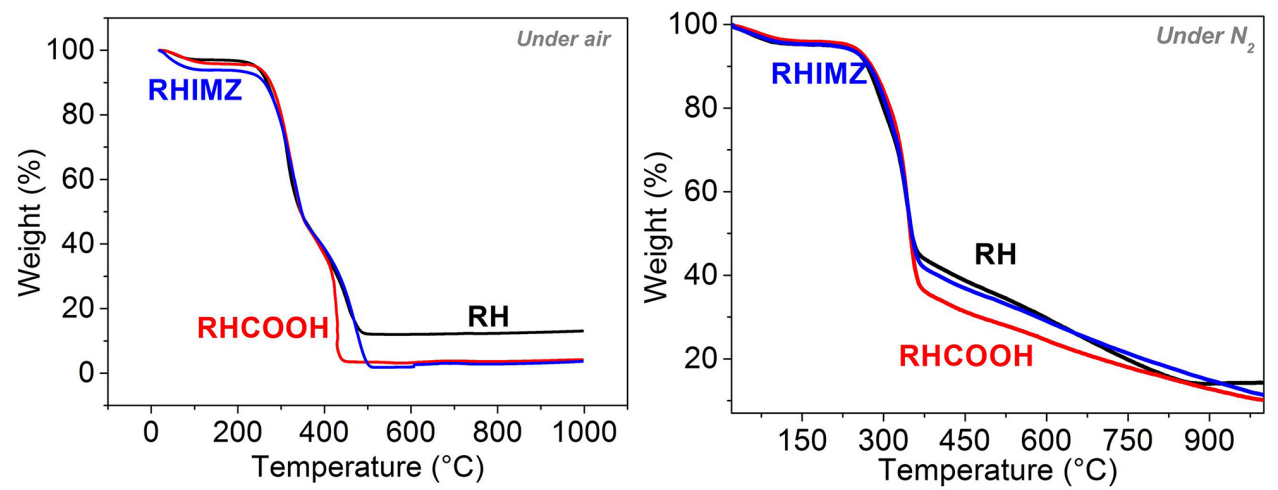

Figure 4. TGA analysis under air and $\mathrm{N}_{2}$ atmosphere for RH, RHCOOH and RHIMZ.

the samples continually loss mass above $350{ }^{\circ} \mathrm{C}$, due to cellulose degradation. In agreement with air analyses, RHCOOH also showed lower thermal stability than RH, in contrast to RHIMZ, that degraded at higher temperatures.

Overall, characterization results combined are consistent with the functionalization's carried out in $\mathrm{RHCOOH}$ and RHIMZ. The low degree of functionalization was purposely projected to guarantee the heterogeneous nature of the final sample targeting catalysis. We show in the following that the catalytic results are also consistent with the functionalization, since RHIMZ showed prominent catalysis and the absence of IMZ groups leads to no catalytic effects. Moreover, to the best of our knowledge, the proposed functionalization of RH is novel and no reports as catalysts have been found. Hence, our study can be extended to other applications foreseeing the sustainable reuse of RH waste.

\section{Catalytic results}

In order to evaluate the potential of RHIMZ as a catalyst for OP degradation, its reaction with the model triester DEDNPP was followed and the kinetic profile obtained at different $\mathrm{pH}$ is presented in Figure 5. The plateau observed for RHIMZ at $\mathrm{pH}$ ca. 7 indicates the higher reactivity of neutral IMZ species, with a rate constant of $\mathrm{k}_{\text {RHIMZ }}=0.43 \mathrm{~s}^{-1} \mathrm{~g}^{-1}(\mathrm{pH} 7.5)$, that is nearly $4 \times 10^{5}$-fold higher than the spontaneous reaction with water. ${ }^{16}$ The reaction with $\mathrm{RHCOOH}$ was also followed but is not shown since it did not show significant catalytic activity. If we compare to IMZ (shown for comparison in Figure 5), RHIMZ is 25-fold more efficient, which is impressive since we are comparing a heterogeneous (RHIMZ) with a homogenous (IMZ) reaction, a trend not commonly found. Indeed, the highly soluble IMZ is expected to react faster than a heterogeneous catalyst. ${ }^{19}$ This difference should be even higher since for determining $\mathrm{k}_{\text {RHIMZ }}$ we consider the mass of RHIMZ and not solely the reactive IMZ groups. The high reactivity of RHIMZ was compared to some catalysts we designed specifically for DEDNPP degradation: graphene nanocatalyst $\left(\mathrm{k}_{\mathrm{N}}=1.46 \times 10^{-2} \mathrm{~s}^{-1} \mathrm{~g}^{-1}\right){ }^{19}$ polivinylimidazole $\left(\mathrm{k}_{\mathrm{N}}=5.22 \times 10^{-3} \mathrm{~s}^{-1} \mathrm{~g}^{-1}\right)^{38}$ and gum arabic derived catalyst $\left(\mathrm{k}_{\mathrm{N}}=1.66 \times 10^{-2} \mathrm{~s}^{-1} \mathrm{~g}^{-1}\right),{ }^{20}$ evidencing that the catalyst obtained from waste, namely RHIMZ, is surely the best catalyst, with a rate constant at least one order of magnitude higher than the other catalysts.

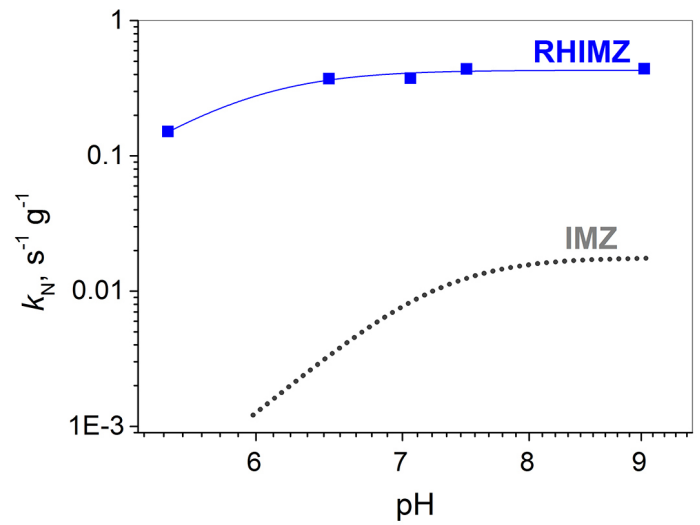

Figure 5. $\mathrm{pH}$ rate profile for the reaction of RHIMZ with DEDNPP $\left(2.0 \times 10^{-5} \mathrm{~mol} \mathrm{~L}^{-1}\right), 25^{\circ} \mathrm{C}$. Data for IMZ are shown for comparison purposes. ${ }^{16}$ The line is shown to guide eyes.

Given the high reactivity of RHIMZ, we pursued the degradation of the real-life pesticide Paraoxon, which is prohibited in many countries but is still found in many food samples. Reactions with Paraxon were followed differently due to its high stability (spontaneous lifetime $=1$ million years). We maintained RHIMZ in $2 \mathrm{~mL}$ of buffered solution at $\mathrm{pH} 8.0$ with Paraoxon $\left(6 \times 10^{-5} \mathrm{~mol} \mathrm{~L}^{-1}\right)$, under magnetic stirring for twenty days and then calculated the degraded amount of Paraoxon by UV-Vis spectroscopy. We already followed the reactions of Paraoxon consecutively (first-order kinetics) and show that the procedure presented here gives the same result, but avoids daily contact with the pesticide. RHIMZ also evidenced a high reactivity with the pesticide, thus, degrading $60 \%$ of Paraoxon in 20 days. This 
gives a rate constant of $\mathrm{k}_{\mathrm{N}}=1 \times 10^{-3} \mathrm{~s}^{-1} \mathrm{~g}^{-1}$, that furnishes a $10^{7}$-fold enhancement, among the highest already reported and even higher than IMZ $\left(\mathrm{k}_{\mathrm{N}}=1 \times 10^{-5} \mathrm{~s}^{-1} \mathrm{~g}^{-1}\right){ }^{18}$

Overall, results show that RHIMZ is efficient for OP degradation, specifically DEDNPP and the pesticide Paraoxon. Based on previous studies, ${ }^{16,20}$ we propose the mechanism presented in Figure 6 where the IMZ group attacks the phosphorus atom of $\mathrm{OP}$, leading to the phenolate product $\left(\mathrm{RO}^{-}\right)$and a phosphorylated intermediate which is unstable and hydrolyses easily in water, giving the less toxic OP derivative. Moreover, by this mechanism, RHIMZ is regenerated, hence confirming the catalytic character. The lower reactivity of IMZ in contrast to RHIMZ indicates synergism that could be accounted to hydrophobic attraction of the reactants by RHIMZ backbone. In addition, neighboring groups on RHIMZ domains can assist the reaction by general acid-base catalysis, typical in biological enzymes, thus suggesting that RHIMZ acts to this extent as an artificial enzyme.

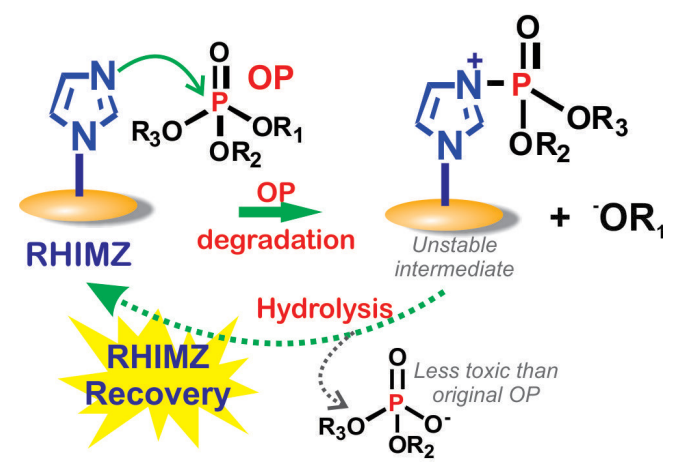

Figure 6. Mechanism proposed for degradation of OP with RHIMZ.

\section{Conclusions}

In summary, we reused a waste of major concern from rice agriculture $(\mathrm{RH})$ for solving an increasing agricultural problem: excessive and inappropriate use of pesticides. We focused mainly on toxic OP pesticides. Firstly, we functionalized RH by carboxymethylation and further anchored IMZ groups on the carboxylate sites by amide bonds. All samples were characterized evidencing successful functionalization. RHIMZ was evaluated as a catalyst for the degradation of the model substrate DEDNPP and further with the pesticide Paraoxon, giving among the highest rate enhancements reported: $10^{5}$ - and $10^{7}$-fold for DEDNPP and Paraoxon, respectively. It should be noted that we targeted low degrees of functionalization in order to guarantee heterogeneity (i.e., higher carboxymethylation would make the RH water-soluble), potentiating RHIMZ as a catalyst. The proposed mechanism confirms the catalytic character by regenerating the catalyst, with a synergism by RHIMZ backbone moieties, suggesting an artificial enzymatic-like nature. Specifically regarding OP, reusing waste such as RH is promising since the source is freely available (waste), the functionalization follows green routes (aqueous medium and at room temperature) and provides a noble use that is catalysis. The results are encouraging for developing environmentally friendly low-cost detoxification processes (i.e., degradation) of prohibited pesticides such as Paraoxon, which still represent large stocks. The process can even be extended to OP chemical warfare, a worldwide matter that has attracted increasing interest. ${ }^{15}$ Likewise, the approach is appealing for projecting sensors for monitoring OP. Finally, the targeted functionalization of RH shown is a novel reuse of $\mathrm{RH}$ waste with great potential that can broaden to other functionalities, seeking other applications.

\section{Supplementary Information}

Supplementary information (absorbance $v s$. time profiles, UV-Vis spectra and complementary thermogravimetric analysis) is available free of charge at http://jbcs.sbq.org.br as a PDF file.

\section{Acknowledgments}

The authors are grateful to CNPq, CAPES, L'OréalUNESCO-ABC, Fundação Araucária, PIBIC/CNPq/UFPR and UFPR for financial support.

\section{References}

1. Moraes, C. A. M.; Fernandes, I. J.; Calheiro, D.; Kieling, A. G.; Brehm, F. A.; Rigon, M. R.; Berwanger, J. A.; Schneider, I. A. H.; Osorio, E.; Waste Manage. Res. 2014, 32, 1034.

2. Jackson, M. G.; World Anim. Rev. 1977, 25.

3. http://faostat.fao.org/ accessed in February 2017.

4. Sarangi, M.; Bhattacharyya, S.; Behera, R. C.; Phase Transitions 2009, 82, 377.

5. Vassilev, S. V.; Baxter, D.; Andersen, L. K.; Vassileva, C. G.; Morgan, T. J.; Fuel 2012, 94, 1.

6. Bruinsma, J.; World Agriculture: Towards 2015/2030: an FAO Perspective; Earthscan: London, 2003.

7. Organization for Economic Cooperation and Development (OECD); OECD-FAO Agricultural Outlook; OECD Publishing: Paris, 2015.

8. Organization for Economic Cooperation and Development (OECD); OECD Environmental Performance Reviews: Brazil 2015; OECD Publishing: Paris, 2015.

9. Organization for Economic Cooperation and Development (OECD); OECD Compendium of Agri-Environmental Indicators; OECD Publishing: Paris, 2013. 
10. Ray, D. K.; Mueller, N. D.; West, P. C.; Foley, J. A.; Plos One 2013, 8, e66428.

11. Carneiro, F. F.; Pignati, W.; Rigotto, R. M.; Augusto, L. G. S.; Rizollo, A.; Muller, N. M.; Alexandre, V. P.; Friedrich, K.; Mello, M. S. C.; Dossiê ABRASCO-Um Alerta sobre os Impactos dos Agrotóxicos na Saúde; ABRASCO: Rio de Janeiro, 2012.

12. Silva, G. R.; Borges Jr., I.; Figueroa-Villar, J. D.; de Castro, A. T.; Quim. Nova 2012, 35, 2083.

13. Santos, V. M. R.; Donnici, C. L.; DaCosta, J. B. N.; Caixeiro, J. M. R.; Quim. Nova 2007, 30, 159.

14. Delfino, R. T.; Ribeiro, T. S.; Figueroa-Villar, J. D.; J. Braz. Chem. Soc. 2009, 20, 407.

15. Yang, Y. C.; Baker, J. A.; Ward, J. R.; Chem. Rev. 1992, 92, 1729.

16. Orth, E. S.; Wanderlind, E. H.; Medeiros, M.; Oliveira, P. S. M.; Vaz, B. G.; Eberlin, M. N.; Kirby, A. J.; Nome, F.; J. Org. Chem. 2011, 76, 8003.

17. Domingos, J. B.; Longhinotti, E.; Machado, V. G.; Nome, F.; Quim. Nova 2003, 26, 745.

18. Orth, E. S.; Almeida, T. G.; Silva, V. B.; Oliveira, A. R. M.; Ocampos, F. M. M.; Barison, A.; J. Mol. Catal. A: Chem. 2015, $403,93$.

19. Orth, E. S.; Fonsaca, J. E. S.; Almeida, T. G.; Domingues, S. H.; Ferreira, J. G. L.; Zarbin, A. J. G.; Chem. Commun. 2014, 50, 9891.

20. Ferreira, J. G. L.; Grein-Iankovski, A.; Oliveira, M. A. S.; Simas-Tosin, F. F.; Riegel-Vidottia, I. C.; Orth, E. S.; Chem. Commun. 2015, 51, 6210.

21. Campos, R. B.; Menezes, L. R. A.; Barison, A.; Tantillo, D. J.; Orth, E. S.; Chem.-Eur. J. 2016, 22, 1.

22. Heydarzadeh, H. D.; Najafpour, G. D.; Nazari-Moghaddam, A. A.; World Appl. Sci. J. 2009, 6, 564.
23. Orth, E. S.; Ferreira, J. G.; Fonsaca, J. E.; Blaskievicz, S. F.; Domingues, S. H.; Dasgupta, A.; Terrones, M.; Zarbin, A. J.; J. Colloid Interface Sci. 2016, 467, 239.

24. Martell, A. E.; Motekaitis, R. J.; Determination and Use of Stability Constants, $2^{\text {nd }}$ ed.; VCH Publishers: New York, 1992.

25. Toğrul, H.; Arslan, N.; Carbohydr. Polym. 2003, 54, 73.

26. Charpentier, D.; Mocanu, G.; Carpov, A.; Chapelle, S.; Merle, L.; Müller, G.; Carbohydr. Polym. 1997, 33, 177.

27. ASTM D1439-94: Standard Test Methods for Sodium Carboxymethylcellulose, Philadelphia, 1994, p. 291.

28. Cowgill, R. W.; Anal. Chem. 1955, 27, 1521.

29. Johar, N.; Ahmad, I.; Dufresne, A.; Ind. Crops Prod. 2012, 37, 93.

30. Roy, D.; Guthrie, J. T.; Perrier, S.; Macromolecules 2005, 38, 10363.

31. Tran, C. D.; Mututuvari, T. M.; ACS Sustainable Chem. Eng. 2016, 4, 1850.

32. Benkaddour, A.; Journoux-Lapp, C.; Jradi, K.; Robert, S.; Daneault, C.; J. Mater. Sci. 2014, 49, 2832.

33. Ndazi, B.; Karlsson, S.; Tesha, J.; Nyahumwa, C.; Composites, Part A 2007, 38, 925.

34. Maiti, S.; Dey, S.; Purakayastha, S.; Ghosh, B.; Bioresour. Technol. 2006, 97, 2065.

35. Aly, A. S.; Sokker, H. H.; Hashem, A.; Hebeish, A.; Am. J. Appl. Sci. 2005, 2, 508.

36. Rajesh, S.; Maheswari, P.; Senthilkumar, S.; Jayalakshmi, A.; Mohan, D.; Chem. Eng. J. 2011, 171, 33.

37. Kalderis, D.; Bethanis, S.; Paraskeva, P.; Diamadopoulos, E.; Bioresour. Technol. 2008, 99, 6809.

38. Orth, E. S.; Campos, R. B.; J. Braz. Chem. Soc. 2016, 27, 285.

Submitted: November 28, 2016

Published online: February 14, 2017

\section{Additions and Corrections}

Page 1765:

Where it reads

“.... $\mathrm{k}_{\text {RHIMZ }}=0.43 \mathrm{~s}^{-1} \mathrm{~g}^{-1}(\mathrm{pH} 7.5)$, that is nearly $4 \times 10^{5}$-fold higher than the spontaneous reaction with water. ${ }^{1{ }^{1}}$ "

Should be read

“... $\mathrm{k}_{\text {RHIMZ }}=0.43 \mathrm{~min}^{-1} \mathrm{~g}^{-1}(\mathrm{pH} 7.5)$, that is over $10^{5}$-fold than the spontaneous reaction with water. ${ }^{16}$,

\section{Page 1765:}

Where it reads

“...graphene nanocatalyst $\left(\mathrm{k}_{\mathrm{N}}=1.46 \times 10^{-2} \mathrm{~s}^{-1} \mathrm{~g}^{-1}\right),{ }^{19}$

polivinylimidazole $\left(\mathrm{k}_{\mathrm{N}}=5.22 \times 10^{-3} \mathrm{~s}^{-1} \mathrm{~g}^{-1}\right)^{38}$ and gum arabic derived catalyst $\left(\mathrm{k}_{\mathrm{N}}=1.66 \times 10^{-2} \mathrm{~s}^{-1} \mathrm{~g}^{-1}\right),{ }^{20}$ evidencing that the catalyst obtained from waste, namely RHIMZ, is surely the best catalyst, with a rate constant at least one order of magnitude higher than the other catalysts."

Should be read

“...graphene nanocatalyst, ${ }^{19}$ polivinylimidazole ${ }^{38}$ and gum arabic derived catalyst, ${ }^{20}$ evidencing that the catalyst obtained from waste, namely RHIMZ, is surely among the best catalyst." 
Page 1765, Figure 5:

Where it reads

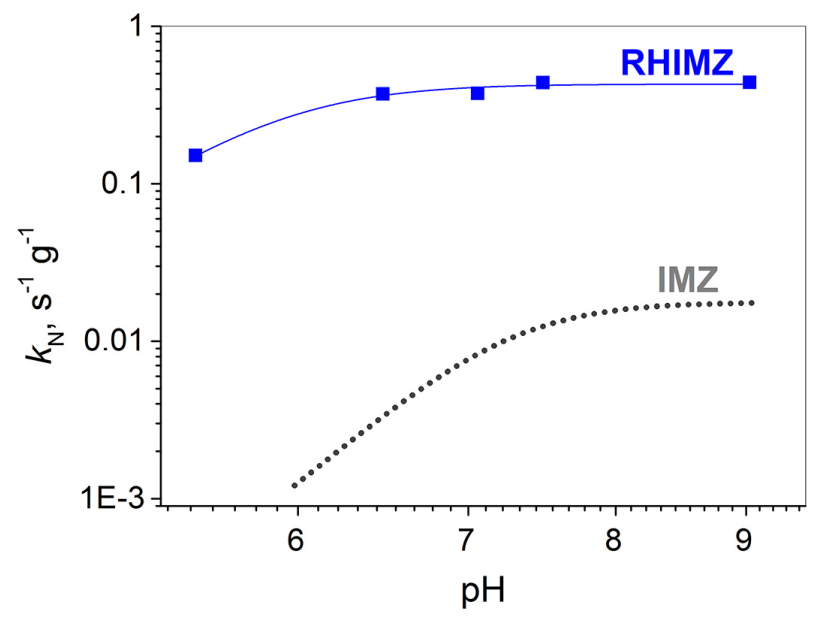

Figure 5. $\mathrm{pH}$ rate profile for the reaction of RHIMZ with DEDNPP $\left(2.0 \times 10^{-5} \mathrm{~mol} \mathrm{~L}^{-1}\right), 25{ }^{\circ} \mathrm{C}$. Data for IMZ are shown for comparison purposes.

Should be read

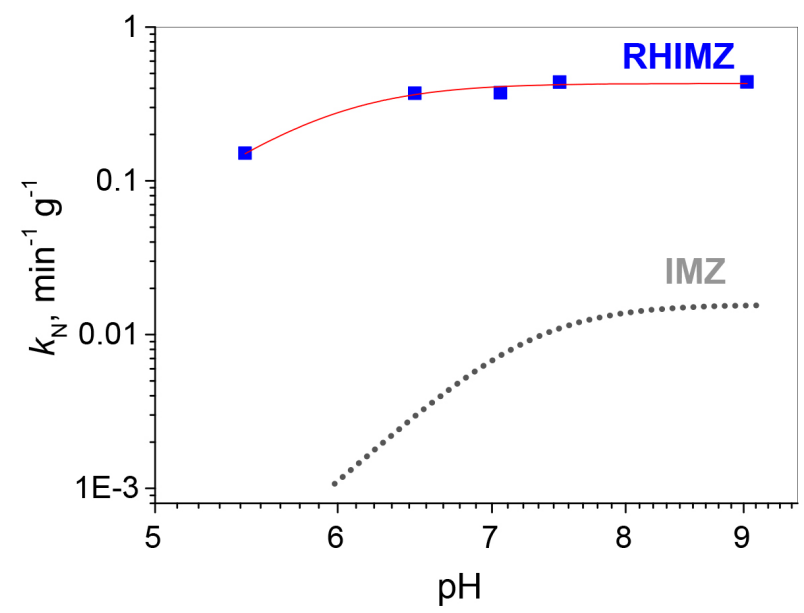

Figure 5. $\mathrm{pH}$ rate profile for the reaction of RHIMZ with DEDNPP $\left(2.0 \times 10^{-5} \mathrm{~mol} \mathrm{~L}^{-1}\right), 25^{\circ} \mathrm{C}$. Data for IMZ are shown for comparison purposes.
Page 1766:

Where it reads

"... gives a rate constant of $\mathrm{k}_{\mathrm{N}}=1 \times 10^{-3} \mathrm{~s}^{-1} \mathrm{~g}^{-1}$, that furnishes a $10^{7}$-fold enhancement, among the highest already reported and even higher than IMZ $\left(\mathrm{k}_{\mathrm{N}}=1 \times 10^{-5} \mathrm{~s}^{-1} \mathrm{~g}^{-1}\right) .{ }^{18}$ "

Should be read

“...gives a rate constant of $\mathrm{k}_{\mathrm{N}}=6.36 \times 10^{-3} \mathrm{~min}^{-1} \mathrm{~g}^{-1}$, that furnishes over $10^{7}$-fold enhancement, among the highest already reported and even higher than IMZ. ${ }^{18}$,

J. Braz. Chem. Soc., Vol. 32, No. 12, xxxx, 2021.

http://dx.doi.org/10.21577/0103-5053.20210141 